\title{
Contornos de sostenibilidad en la práctica docente
}

Francisco Javier Acosta Collazo

Tenemos que encaminar nuestro mundo hacia un desarrollo más sostenible.

Sin embargo, hacer realidad (y enseñar)

la sostenibilidad sigue siendo un desafio vital.

Sin educación, no puede haber desarrollo sostenible.

UNESCO

\section{Sostenibilidad, diversidad de concepciones}

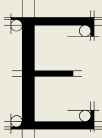
y de la crisis ambiental global, fue creado en la Comisión Mundial sobre Medio Ambiente y Desarrollo un documento llamado Nuestro futuro común (Informe Brundtland), en donde se señala que el desarrollo y medio ambiente no pueden estar separados, plantea el desafío de obtener al mismo tiempo la sostenibilidad económica, la ecológica y la social. En dicho informe se define el desarrollo sostenible como "el desarrollo que satisface las necesidades actuales sin comprometer la capacidad de las futuras generaciones de satisfacer sus propias necesidades" (Universidad para la Paz et al., 2002: 32).

Una vez que surgió el concepto de sostenibilidad, el término fue utilizado en un gran número de entornos socioambientales, de tal manera que "la noción de sostenibilidad se ha ido divulgando y vulgarizando hasta formar parte del discurso oficial y del lenguaje común. Empero más allá del mimetismo discursivo que ha generado el uso retórico del concepto, no ha definido un sentido teórico y praxeológico ${ }^{2}$ capaz de unificar las vías de transición hacia la sustentabilidad"s (Leff, 2000: 19).

\footnotetext{
1 Para un análisis profundo del informe y el documento oficial de la Cumbre de la Tierra, véase el texto en Universidad para la Paz et al., 2002.

2 Es claro que el concepto de sostenibilidad representa enormes dificultades para la acción o praxis.

3 El término sostenibilidad fue generalizado a partir de traducciones de la palabra inglesa sustainable.
}

El desarrollo sostenible plantea preguntas clave que debemos considerar: ¿desarrollo para quién?, ¿desarrollo para qué?, ¿cómo? Novo (2006: 166) señala: "Como vemos, el modelo desarrollista propio de la Modernidad, agudizando sus excesos en las últimas décadas, no tiene mucho de sostenible", por lo que sugiere otro modelo que deberá estar basado en distintos estilos y estrategias para la apropiación, gestión de los bienes y distribución del acceso a los recursos por parte de todos los grupos humanos.

Sin pretender ahondar en la complejidad y controversias sobre el desarrollo sostenible o sostenibilidad, ${ }^{4}$ es importante destacar que, finalmente, los lineamientos internacionales permean en el contorno político-educativo. Así, en el contorno internacional, la UNESCO señala en su portal ${ }^{5}$ que la Educación para el Desarrollo Sostenible (EDS) permite que cada ser humano adquiera los conocimientos, las competencias, las actitudes y los valores necesarios para forjar un futuro sostenible.

Educar para el desarrollo sostenible significa incorporar los temas fundamentales del desarrollo sostenible a la enseñanza y el apren-

4 Podríamos preguntarnos, además, sobre la diferencia entre desarrollo sostenible y sostenibilidad. La sostenibilidad suele considerarse como un objetivo a largo plazo (es decir, un mundo más sostenible), mientras que el desarrollo sostenible se refiere a los muchos procesos y caminos que existen para lograr ese objetivo, por ejemplo, la agricultura y silvicultura sostenible, la producción y consumo sostenible, el buen gobierno, la investigación y transferencia tecnológica, la educación y formación, etcétera (UNESCO, 2012).

5 http://www.unesco.org/new/es/our-priorities/sustainabledevelopment/. 
dizaje, por ejemplo, el cambio climático, la reducción del riesgo de desastres, la biodiversidad, la reducción de la pobreza y el consumo sostenible. La EDS exige métodos participativos de enseñanza y aprendizaje que motiven a los alumnos y les doten de autonomía, a fin de cambiar su conducta y facilitar la adopción de medidas en pro del desarrollo sostenible [...] (UNESCO, 2012).

Se destaca en lo anterior el énfasis de los métodos participativos de enseñanza-aprendizaje que dan importancia y validez a las competencias educativas, algunas de las cuales se vinculan a la dimensión de la sostenibilidad.

En el contexto de las Instituciones de Educación Superior (IES), Bravo (en Vergara et al., 2010: 178) destaca avances importantes en la vinculación de la educación superior con la perspectiva ambiental y de sostenibilidad en ámbitos como la institucionalización, formación e investigación en temas ambientales.

La Reforma Integral de la Educación Media Superior (RIEMS, Acuerdo 444, 2008, Cap. II.) especifica la competencia genérica número 11 : Contribuye al desarrollo sustentable de manera crítica, con acciones responsables, lo cual es un indicador de los lineamientos a seguir en ese nivel.

Estas concepciones incluyen los aspectos ambientales, económicos y político-sociales que son un fundamento para trabajar en forma interdisciplinaria, así como para la promoción de la transversalidad en la temática. Se destaca, además, una visión "resolutista" en donde pueden ser aplicadas estrategias metodológicas como el aprendizaje por proyectos, el aprendizaje basado en problemas y el método de casos, las cuales son factibles de aplicar en el contexto educativo de la institución.

\section{Sostenibilidad en la institución}

En el Ideario, la UAA considera la sostenibilidad como parte de la misión institucional:

La misión de la Universidad Autónoma de Aguascalientes consiste en formar a los estudiantes desde una perspectiva humanista que enfatiza el desarrollo equilibrado e integral de las dimensiones de su persona, lo cual les permita desempeñarse exitosamente como futuros profesionales y vivir la vida con plenitud y calidad; en generar, gestionar y aplicar conoci- miento que responda a necesidades del contexto que derive en su permanente mejora... Todo ello con el propósito fundamental de contribuir al desarrollo sustentable de Aguascalientes y de México [sic]. (uaA, 2008: 1).

Un ejemplo de la perspectiva ambiental en la institución es el Premio al Mérito Ecológico 2012 en la categoría Educación Ambiental Formal, emitido por una dependencia federal (SEMARNAT), y el proyecto "Universidad Verde Sustentable", que coordina los diferentes programas ambientales institucionales, así como la implementación del Sistema de Gestión Ambiental ISO 14001 (UAA, 2013).

Aunado a lo anterior, el Centro de Educación Media (CEM) incluye en el curriculum desde hace más de una década la asignatura de Ecología y Educación Ambiental, y siguiendo los lineamientos emitidos de la RIEMs se integra además en el nuevo curriculum por competencias la asignatura Ecología y Desarrollo Sustentable, que especifica los saberes procedimentales y declarativos vinculados con la sostenibilidad.

\section{Experiencias de aprendizaje}

Actualmente, se demandan cambios en la dinámica de los aprendizajes, así como habilidades para resolver problemas del entorno real de los estudiantes. Este entorno incluye la problemática económica y socioambiental, de ahí la importancia de implementar estrategias didácticas vinculadas con la sostenibilidad.

En el Modelo Educativo Institucional de la UAA (2007: 11) se hace énfasis en que la enseñanza "fomenta la conciencia de la responsabilidad social, la identidad nacional, el respeto a la vida y al medio ambiente", y se resalta la importancia de las experiencias de aprendizaje, además, la educación ambiental (EA) promueve en los diferentes niveles educativos las experiencias que pretenden promover la cultura ambiental, la creatividad y el pensamiento crítico.

Como parte de las experiencias en EA, en el CEM se aplica la estrategia enfocada al aprendizaje por proyectos, en donde los productos de aprendizaje se presentan ante la comunidad educativa en un foro anual denominado Encuentro de Experiencias en Educación Ambiental, el cual es organizado por la academia de profesores. En dicho evento se visualiza cómo los estudiantes trasladan los saberes a su entorno inmediato, en donde se logra un acerca- 
miento a la problemática socioambiental, y además incorporan saberes de otras disciplinas. Los proyectos pueden compartir conceptos y percepciones de diferentes disciplinas, de manera que "permiten a los estudiantes valorar las implicaciones ambientales, sociales y éticas de la educación ambiental" (Acosta, 2002: 206).

Así, las experiencias apoyadas en estrategias educativas bien diseñadas y vinculadas a modelos con el enfoque constructivista, sociocultural y situado, como son los proyectos, el aprendizaje basado en problemas y el método de casos, representan una buena oportunidad para incorporar los temas vinculados a la sostenibilidad en las diferentes áreas del conocimiento.

\section{Algunas conclusiones}

Los indicadores ambientales, económicos y sociales nos dicen que nuestro modelo actual de progreso es insostenible, por lo que entre los retos actuales se encuentra la Educación para el Desarrollo Sostenible que plantea la UNESCO. Entre la diversidad de concepciones, la sostenibilidad significa un balance entre los aspectos sociales, económicos y ambientales con los aspectos culturales.

Al definir la sostenibilidad como parte de un propósito fundamental, la institución puede considerarse como uno de los pilares fundamentales para la construcción de un presente y un futuro sostenible, sin embargo, se requiere hacer explícitos y eficientes los planes y acciones sostenibles en términos educativos, prácticos y éticos.

E. Leff (2010: 172) señala que "La posible construcción de un futuro sustentable habrá de darse en la arena política. Pero la escuela puede ser el mejor laboratorio, el mejor espacio de experimentación y de formación para este cambio civilizatorio", así, la incorporación de estrategias de la enseñanza situada vinculada a la sostenibilidad representa una alternativa viable para una cultura ambiental mínima, de manera que el estudiante pueda formarse con criterios de opinión y tomar decisiones en torno a la problemática ecológica y socioambiental de su entorno.

\section{Fuentes de consulta}

Acosta F. (2002). El proyecto de aula: Una experiencia compartida en el NMS. En UAA, Memoria. Educación ambiental para un desarrollo sustentable. Taller de especialistas y $2^{\circ}$ Foro nacional. Aguascalientes: UAA.

(2012). Construcción de Competencias para la Sustentabilidad en el Centro de Educación Media. En UAA, Memoria. $3^{\text {er }}$ Encuentro Internacional Educativo, Gestión del currículo por competencias. Aguascalientes: UAA.

Díaz Barriga, F. (2006). Enseñanza situada: vínculo entre la escuela y la vida. México: McGraw Hill.

Leff, E. (2000). Saber ambiental: sustentabilidad, racionalidad, complejidad, poder. México: Siglo XXI Editores.

(2010). Discursos sustentables. México: Siglo XXI Editores.

Novo, M. (2006). El desarrollo sostenible, su dimensión ambiental y educativa. España: Prentice Hall.

UAA. (2007). Modelo Educativo Institucional (MEI). Recuperado el 27 de julio de 2012, de http:// www.uaa.mx/direcciones/dgdp/defaa/descargas/modelo_educativo_folleto_mayo.pdf.

UAA. (2008). Ideario de la Universidad Autónoma de Aguascalientes. Recuperado el 20 de agosto de 2012, de https://www.uaa.mx/nu/.

UAA. (2013). Segundo Informe Anual de Actividades del período 2011-2013. México: UAA.

UASLP. (2011). Un mundo en transición. Perspectivas de sustentabilidad para la educación superior. México: UASLP.

Universidad para la Paz et al. (2002). La cumbre de la Tierra eco 92, Visiones diferentes. Recuperado el 15 de agosto de 2012, de: http://esp.habitants. org/la_via_urbana/habitantes_en_la_cumbre_ de_los_pueblos-rio_20/background/la_cumbre_de_la_tierra_eco_92_-_visiones_diferentes

UNESCO. (2012). Educación para el desarrollo sostenible. Consultado el 12 de julio de 2012, en http://www.unesco.org/new/es/our-priorities/sustainable-development/.

Vergara, M. et al. (Coords.). Estrategias Educativas e Institucionales para Sociedades Sustentables. México: Universidad Veracruzana. 